\title{
Exentos de la fiscalidad del General en el Reino de Valencia. La reivindicación de inmunidad por el clero regular
}

\author{
Teresa Canet Aparisi* \\ Universitat de València
}

\section{Resum}

Les relacions entre la Generalitat valenciana i el clergat regular experimentaren fortes tensions al segle XVII amb motiu de l'exempció fiscal dels eclesiàstics, especialment els mendicants. L'anàlisi d'aquests conflictes ens permet apropar-nos a la realitat efectiva d'un privilegi fiscal poc conegut en la seua incidència i derivacions.

Paraules clau: Monarquia Hispànica, Regne de València, clergat regular, fiscalitat, conflicte de competències.

\section{Resumen}

Las relaciones entre la Generalidad valenciana y el clero regular experimentaron fuertes tensiones en el siglo xvir. Surgieron a causa de la exención fiscal de los eclesiásticos, en especial, las órdenes mendicantes. Desde el análisis de estos conflictos nos aproximamos a la realidad efectiva de un privilegio fiscal poco conocido en su incidencia y derivaciones.

* Trabajo realizado dentro del Proyecto de Investigación PGC2018-094150-BC2I, Privilegio, trabajo y conflictividad. La sociedad moderna de los territorios hispánicos del Mediterráneo occidental entre el cambio y las resistencias, financiado por el Ministerio de Ciencia, Innovación y Universidades y la Agencia Estatal de Investigación, y cofinanciado con fondos FEDER. 
Palabras clave: Monarquía Hispánica, Reino de Valencia, clero regular, fiscalidad, conflicto de competencias.

\begin{abstract}
Relations between the Valencian Generalitat and the regular clergy experienced strong tensions in the I7th century. They arose because of the tax exemption of the ecclesiastics, especially the mendicant orders. From an analysis of these conflicts we consider the practical reality of a little-known tax privilege, in terms of its incidence and derivations.
\end{abstract}

Keywords: Hispanic Monarchy, Kingdom of Valencia, regular clergy, taxation, conflict of competences.

El carácter universal de los impuestos establecidos por la Generalidad valenciana con la finalidad de hacer efectivas las ayudas y servicios otorgados al rey en Cortes constituye un principio generalmente aceptado; sin embargo, su aplicación práctica no fue ni contundente ni uniforme en el tiempo. De hecho, experimentó cambios en los siglos XVI y XVII. Las decisiones de exención aprobadas en la primera de las referidas centurias se alcanzaron con tensiones y fueron causa de enconados conflictos en el siglo XVII. Adentrarnos en esta materia nos permitirá exponer una problemática poco frecuentada como tema de investigación, además de familiarizarnos con fuentes y discursos escasamente explotados.

\title{
I. Del principio general a la casuistica particular
}

La afectación universal de la fiscalidad del General de Valencia fue recogida en la legislación foral en fechas tan tempranas como el primer tercio del siglo XV. Concretamente en I428, a una década de distancia de la constitución de la Diputación del General como órgano permanente, Alfonso $\mathrm{V}$ ratificaba, a petición de los tres brazos reunidos en Cortes, la obligación de satisfacer los impuestos del General, las llamadas «Generalidades», por parte del soberano y sus sucesores, el primogénito real, la reina, «e totes e qualsevols persones, lley, dignitat, condició 
e estat sien, aixi Ecclesiastichs, com seglars, e aixi christians, moros, com juheus e aixi estranys com privats». ${ }^{\mathrm{I}} \mathrm{La}$ disposición coincidía con un cambio en el criterio de asignación de los tipos impositivos que pasaba, de ser una decisión de los diputados, a constituirse en acuerdo de las Cortes. ${ }^{2}$ Derivación lógica de dicha modificación fue la reiteración de la obligación de contribuir a la hacienda foral expresada en todas y cada una de las convocatorias de Cortes en las que se introducían cambios en los impuestos existentes o establecimientos de nuevos conceptos fiscales, como puede comprobarse en las asambleas de I446, I552, I564, I585 o I604, por citar algunos ejemplos. Como también lo fue la inclusión de nuevas figuras o situaciones, expresadas en este caso en el fuero 29 de Cortes de I5IO; allí se daba por sentada la extensión de la fiscalidad del General a los oficiales y ministros del Santo Oficio al tiempo que se solicitaba la sujeción a aquella de telas, municiones y otros productos enviados por el rey a Orán, Bugía y otros territorios conquistados para provisión del ejército. ${ }^{3}$

Los argumentos que fundamentaban el carácter universal de la fiscalidad de la Generalidad valenciana recorrían una escala amplia. Como leyes pactadas por los representantes del reino en Cortes, obligaban a todos los regnícolas, sin excepción. Se trataba, además, de impuestos establecidos para atender "causes universalment necessaries y beneficioses... que fonch per a subvenir als senyors reys en casos de guerres y de urgents necessitats»; ${ }^{4}$ la defensa del reino contra turcos, moros y otros

I. Guillem Ramón Mora de Almenar, Volum e recopilació de tots los furs y actes de cort que tracten dels negocis y affers respectants a la Casa de la Deputació y Generalitat de la Ciutat y Regne de València, en casa de Felipe Mey, València, I625. Desarrollaba con detalle esta premisa en la rúbrica 26 de su obra, bajo título: «De la obligació que tots tenen de pagar los drets del General. Y com també los senyors reys son estats servits contribuyr en dits drets y pagarlos».

2. Ibidem, rub. II, 23, p. 52: "[...] desde les Corts del any mCcCcxxvin fins ara, sempre los drets del general se son anats añadint y imposant en Corts, ab decret dels senyors reys».

3. Ibidem, rub. 26, I5, p. I60. Una disposición convenientemente rescatada por el recopilador de entre los Extravagantes de Fori Regni Valentiae (Valencia, 1547).

4. Ibidem, rub. 26, 8, p. 158. 
enemigos de la fe se señalaba como la necesidad más urgente en aquellos tiempos. El fin a que atendían afectaba a todos por igual y, de ahí, la obligación en conciencia de contribuir.

Premisas tan claras en la voluntad del legislador no debieron de ser compartidas por todos los afectados por estos gravámenes. Casi recién inaugurado el reinado de Carlos I, investido ya como emperador y abiertos diversos frentes internacionales a la monarquía, la resistencia de los eclesiásticos a contribuir provocó tensiones que desembocaron en la publicación de la bula Exposuit nobis de Adriano VI, a instancias del propio soberano, en I522. Es precisamente en este punto donde comienza a perfilarse la entidad de un problema que se arrastraría hasta las postrimerías del régimen foral. Se entendía que los miembros del estamento eclesiástico acudían a Cortes en función de los bienes, jurisdicciones y vasallos que poseían, «como barones», se señalaba en las fuentes documentales. Tributar por ello era una cuestión distinta a afrontar pechos recayentes sobre las personas de condición clerical, consideradas exentas en la sociedad coetánea. 5 La fiscalidad del General se basaba, en el momento de plantearse estas oposiciones, en el tall del drap - que gravaba los tejidos que se cortaban para su consumo en la ciudad y Reino de Valencia- y en el impuesto de la mercadería — que gravaba las mercancías que entraban o salían del Reino- - Estos «derechos viejos» (así llamados cuando a comienzos del XVII se establecieron nuevos conceptos impositivos) suscitaban una oposición cerrada en el ámbito clerical. Poner en contexto estas resistencias ayuda también a comprender mejor el problema.

5. Miguel Bartolomé Salon, Controversia de Iustitia et Iure atque de contractibus et comerciis humanis licitis ac illicitis in disputationem quam habet D(ominus) Thomas secunda sectione secundae partis suae Summae Theologicae (I608), calificaba la inmunidad fiscal del clero como un privilegio de derecho pontificio, no divino; lo habían concedido los papas y habían consentido en ello los príncipes cristianos. Controversiae fue el título con que se publicó la última edición del tratado del agustino Salon, aparecido originalmente como Commentarium in disputationem de iustitiam quam habet Divus Thomam in secunda sectionem secundae partis suae Summae Theologicae... copiose explicatur (Valencia, I59I-I598). 
Desde la época de los Reyes Católicos, las empresas de la monarquía habían exigido crecientes aportaciones económicas por parte de un clero que tributaba también a la Cámara Apostólica. ${ }^{6}$ Con ello, a la reforma beneficial, los impuestos de cruzada, tercia de cruzada (para la guerra de Granada), tercia sobre causas pías, jubileos, anata, espolio, subsidio y colecturía, debidos a la Cámara Apostólica, se sumaban la cruzada, el diezmo, la tercia real de los diezmos o el subsidio debidos a la Corona. La dimensión imperial de la Monarquía Hispánica con el advenimiento de Carlos I incrementó las necesidades financieras de la Corona que se tradujeran en peticiones de colaboración a los reinos y, en consecuencia, derrama de impuestos (tacha) desde las haciendas de los territorios (Generalidad o Diputación del General, en el caso de Valencia), afectación de personas e instituciones, y la consiguiente reacción del clero que comentamos. Si a esta situación ańadimos la reforma del clero regular -iniciada a comienzos del siglo xvi para culminar durante el reinado de Felipe II-, con la imposición de la observancia sobre el conventualismo y la consiguiente enajenación de propiedades, beneficios y recursos económicos en determinadas órdenes religiosas, completaremos el marco de referencia de la cuestión analizada. Los miembros de las órdenes mendicantes, abrazando las reglas estrictas de renuncia y pobreza propias, atravesarían especiales dificultades para afrontar exigencias fiscales de cualquier tipo.

Fue en ese marco donde la bula de I522 vino a cancelar la inmunidad fiscal del clero, obligando a los miembros del estamento, cualquiera que fuera su condición, a pagar los derechos del General. Para hacer realmente efectiva la disposición papal, el maestre de Montesa, Bernat Despuig, y el canónigo de la Seo, Cristóbal de la Torre —a la sazón diputados por el brazo eclesiástico-, fueron designados jueces y comisarios para poner en ejecución los contenidos de la disposición papal y castigar a quienes resistieran su cumplimiento.

6. Sobre las aportaciones económicas del clero, Tarsicio de AzconA, «Reforma del episcopado y del clero en España en tiempo de los Reyes Católicos y de Carlos V», en R. García Villoslada, dir., Historia de la Iglesia en España. Vol. III, I ${ }^{o}$. La Iglesia en la España de los siglos XV y XVI, Biblioteca de Autores Cristianos, Madrid, I980, especialmente pp. 183-205. 
La actitud de exigencia fiscal estricta se combinó, no obstante, con decisiones de exención, adoptadas en distintos momentos, bien a petición de la Corona, bien a iniciativa de la propia Diputación del General.7 Los derechos civil y canónico reconocían la exención fiscal, a todos los efectos, del romano pontífice, los cardenales y el camarlengo de la curia. Desde I5IO, por fueros del reino, quedaron excluidos del dret del tall los tejidos destinados a las sacristías de cualquier iglesia y los adquiridos por los padres de pobres para las parroquias. El clero regular, y en especial las órdenes mendicantes, sostuvieron una especial batalla para librarse del General de la mercadería y, sobre todo, del tall del drap. No menor fue la resistencia de ministros y oficiales de la Inquisición; originó numerosos enfrentamientos con la Diputación hasta alcanzar la Concordia de 1569, que puso fin a los mismos. Desde entonces, la Corona se haría cargo de las cantidades adeudadas por el Santo Oficio en concepto de "generalidades». ${ }^{8}$ Avanzando en el tiempo (I604), la inmunidad fiscal se extendió a los padres de doce hijos, hasta un límite anual de 3.000 libras. ${ }^{9}$

En este contexto de forcejeos por la exención, la situación de los mendicantes adquirió un singular protagonismo. Parece evidente que el breve de I 522 no produjo los efectos deseados, al menos en esta rama del estamento eclesiástico. Buena prueba de ello fue la petición formulada en Cortes de 1542 para que se obligase a los monasterios franciscanos, al de la Trinidad y otros de la ciudad y Reino de Valencia, a pagar la parte correspondiente de los servicios de Cortes. Por entonces la cuestión ya había entrado en vía judicial, por lo que Carlos I comisionó

7. Las refiere José María Castillo del Carpio, En la periferia del centro. La hacienda de la generalidad valenciana durante el siglo XVI, PUV, Valencia, 2019, pp. 26-38.

8. Ibidem, pp. 29-38 para un análisis más amplio de la complicada problemática que escondía este enfrentamiento. La intervención personal de Felipe II en la negociación de la exención, a través del virrey de Valencia, conde de Benavente, en Archivo Histórico de la Nobleza (AHNOB), Osuna, C. 419, D. 510. La Concordia se recoge en Mora de Almenar, Volum e recopilació, pp. IIO-III.

9. Mora de Almenar, Volum e recopilació, rub. 27, p. 165. La exención fiscal de este grupo tenía un límite de 3.000 libras anuales. 
para su resolución al duque de Calabria, virrey, auxiliado por dos tachadores de cada brazo y por los abogados de dichos brazos. ${ }^{10}$

La lucha por la exención se prolongó en el siguiente reinado, momento en que la cuestión se complicó con la cuestión del subsidio debido a la Corona, ${ }^{\text {II }}$ tal como acredita la correspondencia mantenida por Felipe II y el virrey conde de Benavente entre los ańos I568 y I570. ${ }^{\text {I2 }}$ La decisión de Pío V (julio, 1567) de otorgar total inmunidad fiscal a los mendicantes atrapó entre dos frentes a las autoridades eclesiásticas valencianas. Los canónigos y el capítulo de la Seo recibieron el motu proprio papal ordenándoles no cobrar ni repartir subsidio entre los monasterios de mendicantes. El monarca quedaba, así, sin un ingreso ya comprometido para el pago de las galeras destinadas a la defensa de la costa, por lo que instó al cabildo a desoír el requerimiento del Papa y ejecutar el reparto correspondiente. La negativa de los eclesiásticos a cumplir el mandato del rey por temor a las censuras papales llevó a Felipe II a utilizar a su representante en el reino, Benavente, para conseguir la exacción debida por los mendicantes. Pero el virrey, a la altura de I570, ni había logrado tal objetivo, ni contaba con medios para alcanzarlo, según manifestó a su regio interlocutor. Por su parte, los diputados valencianos, conocido el motu proprio de 1567, entablaron relación epistolar con sus homónimos de Aragón y Cataluńa para conocer su afectación por esta medida y la respuesta que generó. Para mayor fuerza enviaron un embajador a la Corte para informar de la situación a Felipe II que, a su vez, solicitó consulta al Consejo de Aragón e instó la correspondiente actuación del embajador de la monarquía ante la

IO. Ricardo García CárCel, Cortes del reinado de Carlos I, Edición del Departamento de Historia Moderna de la Universidad de Valencia, Valencia, 1972, pp. I44-I45.

II. Azcona, "Reforma del episcopado", pp. 200-20r. Este fue un ingreso tan pingüe como difícil de imponer y conseguir. Se trataba de una concesión pontificia sobre los beneficios eclesiásticos, convertida en cantidad fija propuesta como subsidio, repartida por diócesis en las asambleas del clero y enviada a los responsables de la Corona. Desde el pontificado de Clemente VII, el clero hispano estuvo «en pie de subsidio y de ayuda a la Corona sin respiro", según el autor.

I2. AHNOB, Osuna, C. 419, D. 90 (Madrid, noviembre, 1568) y 458 (Córdoba, abril, I570) 
Santa Sede. A la acción de este se unió la de Jaime Arrover, enviado a Roma en representación de la Generalidad valenciana. ${ }^{13}$

El análisis de la documentación económica de la Generalidad ha permitido comprobar que desde I57I esta contabilizó el importe de las exenciones recayentes en diferentes órdenes religiosas y en miembros del Santo Oficio. ${ }^{14}$ El montante de estas contabilidades se revertía a las arcas reales, en el caso de miembros de la Inquisición, ${ }^{15} \mathrm{y}$ a las de la Generalidad, en el del clero. Por otro lado, las certificaciones expedidas por el credenciero del General a los diputados constituyen un magnífico escaparate tanto de los diversos productos despachados francos de derechos como de los beneficiarios de la exención. Por estos registros desfilan los frailes y monjas de los conventos de San Francisco, El Remedio, Nuestra Señora de Montserrat, Predicadores, Santa Catalina, San Sebastián, Santa Tecla, Poblet, Carmelitas, Jerusalén, San Miguel de los Reyes, La Puridad, La Encarnación, San Agustín, La Concepción o la Compañía de Jesús, además de los senyors Inquisidors. ${ }^{16} \mathrm{La}$ exención de los regulares fue recogida por el recopilador Mora de Almenar con una anotación que definía bien a las claras el carácter graciable de la concesión; una condición que sería esgrimida como argumento de peso por los abogados de la Diputación en los litigios planteados en el siglo Xviı con el clero regular. Señalaba el jurista:

I3. Archivo del Reino de Valencia (ARV), Generalitat. Lletres misives, I953, ff. I34r-I35r (diciembre, I567) y ff. I52V-I58v (diciembre-febrero, I569). Información aportada por O. Clavell López, que prepara actualmente su tesis doctoral y a quien agradezco me permita utilizarla en este trabajo.

I4. Datos aportados por Castillo del Carpio, En la periferia, p. 28.

I5. Mora de Almenar, Volum e recopilació, pp. I08-I09. El recopilador aporta las órdenes de Felipe II en 25 de junio de 1568 al bayle general de Valencia y al virrey, conde de Benavente, de no cobrar a los miembros del Santo Oficio los impuestos reales de peaje y quema y de abonar a la Generalidad el importe de los que debía haber percibido de los ministros del Santo Oficio.

I6. ARV, Generalitat. Provisions, 3062 (I593). Agradezco a la profesora Emilia Salvador haberme facilitado la documentación citada sobre la que actualmente trabaja. 
Als religiosos, assitents y conventuals, que resideixen en lo present Regne sels dona despaig franch per caritat quels fa la Deputació; y a estos sels porta llibre de compte y rahó y la Deputació refá als arrendadors lo que importa lo dit dret ab certificatòries del dit credencier Vicent Ayerdi, o de son conjunt. Pero los religiosos que son de fora del Regne paguen efectivament lo dret del General. ${ }^{17}$

La «caridad» de la Diputación al clero regular del reino tuvo, sin embargo, una fecha de caducidad; cuando se alcanzó aquella dio principio una batalla judicial desarrollada en las décadas centrales del siglo XVII.

\section{La lucha en los tribunales por la conservación de la inmunidad fiscal}

La documentación generada por los litigios que enfrentaron a la Diputación del General de Valencia y el clero regular ofrece un gran interés tanto en fondo como en forma. Más allá de los procesos propiamente dichos, esta situación de enfrentamiento fue la ocasión para la producción de diversas Alegaciones jurídicas, difundidas de forma impresa y de gran valor para el conocimiento del iter procesal recorrido por la causa. ${ }^{18}$ Estamos ante unos escritos formados en la fase final del

17. Mora de Almenar, Volum e recopilació, rub. 22, p. III.

I8. Teresa CANet Aparisi, «La Diputación del General en la literatura jurídicopolítica valenciana de los siglos Xvi y XviI», en La voz del Reino. Representación política, recursos públicos y construcción del Estado. Congreso Internacional. Valencia, Morella, Alicante, 2I-28 octubre 20I8, en prensa. En dicho trabajo señalé la importancia de estas fuentes documentales para el conocimiento de la institución de referencia; una afirmación extensible a otros organismos y procesos históricos como acredita la producción de estos escritos por parte de importantes juristas del período moderno como Tomás Cerdán de Tallada, Nicolás Bas y Galcerán o Joan Pere Fontanella. Para una consulta más exhaustiva de esta materia, véanse Teresa CANET, Vivir y pensar la politica en una monarquía plural. Tomás Cerdán de Tallada, PUV, Valencia, 2009; Eugenio CísCar Pallarés, «La ferma de dret en el derecho foral valenciano», Anuario de Historia del Derecho Español (AHDE), 62 (1992), pp. 327-354, especialmente nota 
proceso, antes de que se dictase la sentencia. Allí, sus autores, normalmente, abogados, desarrollaban argumentaciones jurídicas a favor de una de las partes del pleito. En general, este tipo de "papeles en Derecho" constaba de dos partes; en la primera se hacía exposición de hechos probados, y en la segunda se planteaban las dudas que aquellos suscitaban y se desarrollaba el discurso jurídico destinado a resolverlas, siempre favorable a la parte defendida. ${ }^{19}$ Esta última parte de la alegación era el marco en el que el abogado-autor desplegaba toda su erudición y conocimientos en derecho y doctrina. Su difusión impresa constituía un medio adecuado para crear opinión o captar futuros clientes y permite ahora conocer los argumentos de autoridad esgrimidos. En el análisis de la cuestión que abordamos nos sirven de base un conjunto de alegaciones elaboradas entre los años I649 y I66I, ${ }^{20}$ un recorrido cronológico que habla por sí solo de la complejidad y dificultad de resolución de la problemática abordada. Afectaban a los franciscanos del Reino de Valencia pero ofrecen también información sobre los mendicantes agustinos y la orden de los jerónimos.

La exención fiscal del clero regular en Valencia no debía de ser una cuestión de menor entidad, habida cuenta del número de establecimientos existentes. Durante el período moderno el reino llegó a contar con I36 conventos; el $45 \%$ de los mismos se concentraba en 8 poblaciones:

33, p. 337; y Josep Capdeferro i Pla, Ciència i experiència. El jurista Fontanella (I575I649) i les seves cartes, Fundació Noguera, Barcelona, 2012.

19. Diversos trabajos han ponderado el valor de estas fuentes documentales. Sirvan como referencia los de Margarita Serna Vallejo, «El régimen legal de las alegaciones jurídicas en la Corona de Castilla y en los reinos de Navarra y de la Corona de Aragón en la baja Edad Media y en época Moderna», Ius Fugit, I7 (2OII-20I4), pp. II-54; Antonio Jordá FernándeZ, "Alegaciones jurídicas del siglo XVII en Cataluña. La obra de Josep Ramón», Ius Fugit, I7 (20II-20I4), pp. 55-IO4; Antonio Planas Roselló, "Las alegaciones jurídicas y otros papeles en derecho» (Mallorca, siglos XVIXIX), Ius Fugit, I7 (20II-20I4), pp. I05-I26; Santos M. Corona GonZÁlez, "Alegaciones e Informaciones en derecho (porcones) en la Castilla del Antiguo Régimen», AHDE, 73 (2003), pp. 165-192.

20. Esta documentación forma parte del fondo existente en la Biblioteca Histórica de la Universidad de Valencia (BHUV) y de la Biblioteca Valenciana (BV). 
Valencia, con 49 establecimientos; Alicante y Orihuela, con I4 cada una; Játiva, con II; Alcira y Segorbe, con 7 cada una; y Castellón y Onteniente, con 6 conventos en cada una de dichas localidades. ${ }^{21}$ Las fechas a partir de las cuales empieza a desarrollarse la problemática que contemplamos también son significativas. Nos sitúan en los años cuarenta del siglo XvII, cuando los frentes internos e internacionales abiertos a la monarquía exigieron mayores esfuerzos militares, traducidos en nuevas contribuciones económicas a los reinos. ${ }^{22}$

La iniciativa en la presentación de Alegaciones para reducir al clero regular a la disciplina fiscal del reino correspondió a la Diputación del General. De la confección de los escritos en defensa de los intereses de aquella se ocupó el pavorde Mathias Morlá. ${ }^{23}$ Llevó a la imprenta dos documentos - el primero de planteamiento y el segundo de réplica a su contrincante- en los que rechazaba la interposición de "firma de derecho" por el representante de los franciscanos ante la Real Audiencia y rebatía el privilegio de inmunidad que esgrimían los mendicantes. ${ }^{24}$ Estamos, pues, ante dos elementos de juicio complementa-

2I. Ángela Atienza López, Tiempo de conventos: una historia social de las fundaciones en la España Moderna, Madrid, Marcial Pons, 2008, pp. 45-48.

22. Presiones que se continuaron, más allá de la Unión de Armas, por medio de continuadas peticiones de servicios que, en casos como el del reino de Cerdeña, contenían especial llamada a la contribución por parte del estamento eclesiástico, como se recoge en Antonio Canales de VEGA, Discursos y apuntamientos sobre la proposición hecha en nombre de su Magestad a los tres Braços Eclesiástico, Militar y Real (Caller, I63I), A. Murtas, ed., con introducción de G. Tore, CUEC, Cagliari, 2006. En especial «Discurso III», pp. 2I-27.

23. Este jurista elaboró Alegaciones en favor de los diputados del General en conflictos de orden diverso. Una cuestión de protocolo con los oficiales reales fue el origen de: A la católica Magestad del rey nuestro señor don Felipe IV el Grande, los diputados del reyno de Valencia proponen la Alegación que en su favor, contra los oficiales reales escribe el doctor Matias Morlá, pavorde de la santa metropolitana iglesia de Valencia, (Valencia, I650), en BHUV, varia 45 (28).

24. BHUV, var. 45 (26). Alegación en derecho en favor de la Generalidad del Reyno de Valencia con el convento del seráfico P. S. Francisco desta ciudad, y otros de la regular observancia (Valencia, I649). Este documento constaba originalmente de 24 capítulos, de los que no se han conservado los números 8 a II. A lo largo de ellos el autor va 
rios. Por el primero se cuestiona la instancia a la que se acoge una de las partes (los franciscanos) para amparar su derecho (no pagar impuesto del corte); en el segundo se tratará de demostrar la vulneración de un deber. Para comprender mejor la doble proyección que tomarán los argumentos jurídicos expuestos por los litigantes, convendrá precisar en qué consistía la ferma de dret o iuris firma, un procedimiento poco estudiado a pesar de su presencia en la legislación foral y la documentación procesal. ${ }^{25}$ Se trata de una iniciativa jurídica destinada a proteger la posesión de un bien o de un derecho en favor de quien la plantea. Se podía presentar ante cualquier tribunal, aunque el juez ordinario era la curia de la Gobernación. Se resolvía por procedimiento sumario.

Situados en el terreno de los hechos — tal como los expuso en su primera Alegación el pavorde Morlá-, en una etapa de arcas saneadas, la Generalidad valenciana, "con zelo piadoso", había hecho "gracia y limosna» a las cuatro órdenes mendicantes, primero, y a otras órdenes religiosas luego, «del derecho del General del corte, que todos los eclesiásticos pagaban a tempore inmemoriali, excepto el Romano Pontífice y las iglesias desta ciudad y reino». La emergencia financiera sobrevenida al General del Reino había llevado a los diputados a retirar tal concesión a partir del I4 de febrero de I642, previa consulta a teólogos y juristas. Las reacciones de los afectados se produjeron entonces en cadena; por el relato recogido en estas Alegaciones conocemos las que protagonizaron los conventos de San Jerónimo de Cotalva, San Agustín y San Francisco, en Valencia. Los agustinos, por medio de fray Francisco Pérez, presbítero, en calidad, también, de síndico de otros conventos,

planteando argumentos y refutaciones. El pavor de Mathias Morlá era hijo del jurista Pedro Agustín Morlá, autor de la obra Emporium utriusque iuris quaestionum in usu forensi admodum frequentium. Prima pars (Valencia, I599). Datos de su curriculum en Vicente Graullera, Juristas valencianos del siglo XVII, Biblioteca Valenciana, Valencia, 2003, p. 259. Era doctor en Derecho; ejerció como abogado de D. Manuel Eixarch, marqués de Benavites, en I637; estuvo vinculado a la cátedra de Leyes (I640) y sería asesor del bayle general de Valencia en 1663.

25. Me remito al mejor conocedor de este procedimiento, Eugenio Ciscar PallaRÉS, "La ferma de dret en el Derecho foral valenciano», AHDE, 62 (1992), pp. 327-354. 
interpusieron firma de derecho pretendiendo que la Real Audiencia se avocase la causa; no tuvieron éxito y su pretensión fue desestimada «a los primeros lances», según Morlá. Por parte de los franciscanos (es la causa que da origen a esta Alegación de Morlá que analizamos), interpuso firma de derecho ante el tribunal de la Gobernación el notario Josep Tudon, el 20 de noviembre de I648, e intentó que, pendiente el juicio de nulidades de la provisión de admisión iuris firma, la Real Audiencia avocase la causa. La pretensión de los franciscanos se sustentaba en dos razones. Consideraban, por una parte, ser la suya causa de menores y pobres mendicantes y, en consecuencia, consistorial y avocable por la Audiencia; por otra, que no se les podía aplicar la disposición del fuero 22 de 1547 que prohibía la interposición de firma de derecho en causas privativas de los diputados porque en el fuero se hablaba de "personas» $\mathrm{y}$ no de comunidades, como era su caso. ${ }^{26}$

Los argumentos del defensor de los franciscanos fueron rebatidos por M. Morlá que esgrimió la jurisdicción privativa de los diputados en todas las causas recayentes en los derechos del General. Esto significaba que ningún otro tribunal o instancia podía entender en ellas, y, caso de intentarlo la parte interesada, la causa debía ser rechazada por el órgano requerido. Sustentaba su criterio en la legislación del reino (fuero 33 de I5IO, 2I y 22 de 1547 y otros recogidos en la rúbrica in de la recopilación de Mora de Almenar) y en actos positivos como las reales provisiones de 1497 y I535, dictadas en juicio contradictorio, además del fallo más reciente de la Real Audiencia rechazando la firma de derecho presentada por el síndico de los agustinos en una causa suscitada por los mismos motivos.

Con relación al segundo de los argumentos de defensa de los franciscanos, Morlá no negaba la existencia de doctrina favorable al reconocimiento del privilegio de menor para la Iglesia y, como derivación de aquel, la facultad de elegir tribunal para mejor defensa de su derecho. ${ }^{27}$ Pero estaba decido a demostrar que el fondo de la cuestión re-

26. BHUV, varia 45 (26), ff. I-2.

27. Contrasta vivamente el cambio de fuentes de autoridad. Frente al despliegue de erudición legal, ahora Morlá irá señalando un elenco de autores, también esgrimi- 
suelta en el fuero 22 de $1547^{28}$ no era otro que la salvaguarda de la jurisdicción privativa de los diputados en causas de la Generalidad. Para el pavorde, el término algunes persones recogido en la disposición evocaba solo la ocasión y motivo del daño que daba lugar a la petición del fuero $y$, aun en el supuesto de admitirse que aquellas palabras formasen parte del mismo, debería entenderse su aplicación tanto a personas verdaderas como ficticias, porque, reconocido que: «la evocación de sí es cosa odiosa", "quando se trata de materia odiosa, si milita la misma razón in casu vero et ficto, ambos se comprehenden en la ley o estatuto ex indemnitate rationis». ${ }^{29}$ En consecuencia, el fuero 22 de 1547 debía interpretarse en sentido extenso, no en el estricto de las palabras «algunas personas». Esa había sido la intención del emperador Carlos I al aprobarlo. De actuar en contrario y admitir la firma de derecho interpuesta por los franciscanos, se menoscabaría la jurisdicción privativa de los diputados, se vulnerarían los fueros que la consagraban y se traicionaría la intención del legislador al aprobar la norma. ${ }^{30}$

dos por la parte contraria, pero cuyas tesis va a reinterpretar en favor de su argumentación procesal. Las citas a Alciato, Alex, el regente Tapia, Covarrubias, Calerval, Loseus, Pichardo, De León, Antonio Faber, Burgos de Paz o Juan Salas, se suceden en su digresión.

28. Transcrito allí: «Item senyor, per quant moltes vegades se segueix que algunes persones del dit regne per escusarse de pagar lo dret del General y per no servar y obtemperar los actes de cort, crides, ni provisions en virtut de aquelles per restrañar dits drets y llevar tota ocasió de fraus fets se posen algunes fermes de dret a suplicació dels quals per lo lloctinent general del dit regne son estades evocades a la Real Audiencia, etc, supliquen los dits tres braços sia merced de vostra Alteza provehir y manar que les causes desus dites de fermes de dret y altres qualsevols tocant les coses $\mathrm{y}$ afers del dit General, directes o indirectes et alias quomodocumque vel qualitercumque, no sien ni puguen eser evocades a la Real Audiencia». BHUV, varia 45 (26), f. 7 .

29. Ibidem, f. 8.

30. Ibidem, f. II. Expresaba su conclusión con esta rotundidad: «la instancia ex adverso suplicada no es evocable a esta Real Audiencia, pues conforme los fueros que se han alegado por esta parte, interpretados con algunos exemplares, es notorio y claro que en ningún tribunal se puede decidir las causas que tocan los derechos de la Generalidad, sino en el de la Diputación, aunque se pretendiese que la evocación 
La réplica a la Alegación de Morlá salió de la pluma del doctor Silvestre Blanco, ${ }^{31}$ cuya orientación en el enfoque de la causa era bien distinta. Inició su escrito concediendo crédito a los argumentos de la parte contraria en relación con oponerse a la avocación de firma de derecho en la causa sobre la exención del tall del drap. Admitía que, en efecto, hasta 1642 los mendicantes no lo habían pagado; que ello se debió a una especial gracia de la Diputación, propiciada por «la mayor felicidad de los tiempos pasados» y que, al cambiar la situación financiera de las arcas del reino, se había restablecido la obligación de pagar un impuesto al que siempre habían estado sujetos los mendicantes al igual que el resto del Estado eclesiástico, excluido el romano pontífice y las iglesias de la ciudad y Reino de Valencia. Reconocía también que los conventos de San Agustín y de San Jerónimo de Cotalva (este en materia de sisas municipales) habían pretendido lo mismo que los franciscanos (mantener la exención) por la misma vía (firma de derecho). Se les denegó el procedimiento, y se declaró la obligación de pagar «sin se poder nadie eximir deste derecho del general, teniendo la Diputación jurisdicción privativa a qualesquier juezes, por preeminentes que sean, para compeler a la paga, según fueros». Reconocía también el argumento esgrimido en los otros casos (Cotalba y San Agustín) sobre que

sería sólo para conocer de las nulidades dichas por Iosef Félix, notario, otro de los subsíndicos de la Generalidad, de la provisión de admissa iuris firma ante el portantveces de general governador, porque en este juicio en que se pretende que no son evocables causas qual esta, se toca la razón de que son privative de los diputados, y así, aun para este fin, no se podría evocar por no ser causa de la jurisdicción desta Sacra Real Audiencia, iuxta notata a domino regente D. Francisco de Leon».

31. BHUV, varia 2 (29), Por la orden de la regular observancia del seráfico P.S. Francisco con la Generalidad del Reino de Valencia. El documento carece de fecha, pero el hecho de que su impresión fuese autorizada por el abogado fiscal Lorenzo Matheu y Sanz y que su contenido responda punto por punto a los argumentos desplegados por Morlá en la Alegación antes analizada, permite datarlo en I649. Su autor, Silverio Blanco (I590-1654) fue asesor ordinario del Justicia civil (I6I8, I627, I630, I636 y I654, fecha de su muerte), conceller jurista (I639 y I640), abogado del mercader Sebastiá Molina (I632), abogado de la villa de Biar (I642) y del duque de Villahermosa. En Graullera, Juristas valencianos, p. I47. 
el «privilegio de la Iglesia (en esta materia) no es de otra especie que el de los menores, miserables y fisco, de cuyas causas tocantes a los derechos de la Generalidad conoce ella misma».32 Pero a pesar de todo ello, Blanco consideró que el caso de los franciscanos no podía equiparse a los anteriores, por una serie de razones.

Para el defensor de los franciscanos, la extrema pobreza de la orden había sido reconocida en textos canónicos y confirmada por el propio Concilio de Trento. Carecían de bienes; vivían de limosna. Diferentes bulas, en especial la de Martín IV, declaraban que hasta el hábito que vestían pertenecía al romano pontífice. Era también doctrina de muchos autores que «ni áun el síndico es de la religión, sino ecónomo de la Silla Apostólica».33 Advertía que, aunque el papa Juan XXII abdicó de sí y de la Santa Sede todo este dominio, sin embargo, Alejandro VI y otros sumos pontífices lo recuperaron y revalidaron, derogando la extravagante ad conditorem por la que el papa Juan la había renunciado. Y, en un contexto más próximo, dado que la bula de Adriano VI recogía expresamente la exención del sumo pontífice con relación a la fiscalidad del General, dicha inmunidad se hacía extensiva a la orden franciscana por el hecho de que la propiedad de sus bienes pertenecía al Papa y que solo el uso de aquellos había quedado para los religiosos en función de socorrer sus necesidades. Recordaba que, si los tributos se pagaban en función de la hacienda y de manera proporcional a ella, quienes nada tenían en nada podían contribuir. Blanco exponía que, por bula de Nicolás IV se probaba que los regulares observantes, tanto los religiosos como los bienes, estaban sujetos a la Silla Apostólica y exentos de cualquier otra jurisdicción. En consecuencia, ni la bula de Adriano VI ni los fueros del reino podían obligarles a pagar derechos del General. Más aún cuando en el documento de I522 se hablaba de clérigos seculares, no regulares; y si regulares, no de mendicantes; y si mendicantes, no de la regular observancia de San Francisco por razón de su especial pobreza e incapacidad para tener rentas ni haciendas.

32. Ibidem, ff. I-2.

33. Ibidem, f. 2. 
A propósito de ello traía a colación otra bula, de Clemente IV, que determinaba que, si algún señor temporal obtenía letras o motu proprio de la Sede Apostólica para que el Estado eclesiástico pagase tributos, si en ellas no se hacía expresa mención de esta «sagrada familia de regular observancia, aquellas serían nulas y sin valor alguno». ${ }^{34}$

Las conclusiones a las que llegaba Blanco eran contundentes. La Diputación no podía apoyarse en la bula de $1522 \mathrm{ni}$ en los fueros del reino para exigir tributos a los franciscanos. No habérselos exigido hasta $\mathrm{I} 642$ no se debió a un acto facultativo de la Generalidad, ni a una especial gracia, liberalidad o limosna: fue una obligación forzosa, derivada de su justo título de exención. Hacer pagar derechos del General a los franciscanos significaba transgredir su regla y privilegios apostólicos. Y existía pena de excomunión para quienes exigiesen tributos a los frailes menores, establecida por disposición de Alejandro IV. Por si ello no bastara, a los franciscanos les asistía la posesión inmemorial de inmunidad fiscal, que se remontaba a su mismo establecimiento en el reino; y, aun no admitiéndose tal inmemorial, el hecho de llevar más de cuarenta años exentos acreditaba tal condición. ¿Podía equipararse este caso con el de jerónimos y agustinos?, se preguntaba el defensor de los franciscanos. En absoluto. Con relación a los primeros, por la diferente naturaleza de las órdenes; en el caso de los agustinos porque, con ser mendicantes, tenían bienes y rentas propias con los que poder pagar tributos. Sin perderse en razonamientos teóricos, Blanco invocaba un fallo reciente del Consejo Real en el pleito movido por el procurador general de los reinos de Castilla y los arrendadores del impuesto de millones con el juez conservador de la orden franciscana. El pleito llegó por vía de fuerza al Consejo Real, donde se falló a favor de la orden en 1633. Desmontaba también el argumento sostenido por Morlá, según el cual la jurisdicción privativa de la Generalidad en materia de derechos propios le confería competencia en causas de pobres, miserables y menores; no era aplicable en este caso, pues, de admitirse, se abriría a esta instancia jurisdicción sobre la orden franciscana, lo cual era im-

34. BHUV, varia 2 (29). 
pensable por su estatuto. También rebatió que no se pudiera apelar o firmar de derecho ante el tribunal supremo del rey, la Real Audiencia, en este tipo de causas en función de la jurisdicción privativa del órgano recaudador. Para fundamentar esta opinión se amparaba en la decisión I47 de Francisco Jerónimo de León, construida a propósito del pleito entre el síndico de Torrent y el de Valencia por el pago de la sisa del vino (I6I4). . $^{35}$

Los argumentos de Silvestre Blanco dieron lugar a la segunda alegación del pavorde Morlá. ${ }^{36}$ En ella el defensor de la Diputación quiso reconducir la cuestión central del debate, que no era la inmunidad fiscal de los franciscanos, como pretendía su adversario, sino la firma de derecho y avocación de la causa a la Real Audiencia. ${ }^{37}$ Resumidos los argumentos del oponente, Morlá se centró en el artículo fundamental: la avocación. La Diputación tenía concedidos fueros a favor de su jurisdicción privativa en materia de sus impuestos; el hecho de que los fueros fuesen leyes temporales no invalidaba su aplicación en causas que afectasen a religiosos. Sostenía que el adversario incurría en contradic-

35. Un análisis de esta en Nuria Verdet, Gobernar con el derecho. Las Decisiones de Francisco Jerónimo de León, Institució Alfons el Magnànim, Valencia, 2019, pp. 23I-243. 36. BHUV, varia 45 (27), Por la iurisdición de los diputados del reino de Valencia, con la orden del seráfico padre san Francisco de la regular observancia (s.f.). Aunque el documento carece de fecha su contenido permite deducir que se elaboró nada más conocerse la respuesta del contrincante antes referida. En cualquier caso, el hecho de que el abogado fiscal que autorizó su impresión fuese - tanto en este caso como en la siguiente respuesta de Silvestre Blanco, también sin fechar- Juan Chrisóstomo Berenguer, nos permite situarlo entre I649 y I65I. Nos inclinamos por la primera de las fechas por la naturaleza de la cuestión que se debate en esta causa (firma de derecho) y por la dinámica curricular de Berenguer que fue el sucesor de L. Matheu en la abogacía fiscal desde junio de i649. En Graullera, Juristas valencianos, p. I47 y Teresa CANet, La magistratura valenciana (s. XVI-XVII), Publicaciones de la Universitat de València, Valencia, 1990, p. 175.

37. BHUV, varia 45 (27), f. I: «la causa que en esta Real Audiencia se trata no es sobre inmunidad y essención que pretenden los religiosos del señor san francisco, sino sobre la evocación de la firma de derecho que el procurador y síndico en nombre de aquellos tiene puesta en la corte del gobernador, y pretende se debe evocar a este Real Consejo con pretexto de que sería consistorial». 
ción cuando alegaba que la firma de derecho no debía decidirse en el tribunal de la Gobernación porque no podían aplicarse leyes temporales a quienes carecían de lo temporal, pero interponía aquella ante la Audiencia, siendo que, en ambos casos, «los fueros y reales privilegios con que decide sus causas leyes son temporales y no eclesiásticas». ${ }^{38}$ Por otro lado, la interpretación del término "personas» reintroducía en el debate el sentido del fuero 22 de I547. Las tesis de Mascardo, Loseo y Barbosa en las que el adversario había pretendido fundamentar su argumento se apartaban, desde el punto de vista de Morlá, de las «decisiones de los Consultos» (Paulo y Ulpiano) que refería en réplica para concluir, como en la alegación anterior, «ser una misma razón la que milita así en la persona verdadera como en la ficta». ${ }^{39}$

El carácter privativo de la jurisdicción de los diputados en materia de fiscalidad del General era subrayado como cuestión básica. Para Morlá, la estrategia del defensor de los franciscanos, al orientar la materia de la causa hacia el tema de la inmunidad y no hacia el conocimiento de la firma de derecho, estaba causando un gravísimo daño a una prerrogativa concedida a la Diputación por los reyes de Aragón. Y también aquí, según apreciaba, incurría en contradicción porque, pese a reconocer la jurisdicción privativa de los diputados en el cobro de impuestos a menores y pobres, negaba la extensión de la prerrogativa sobre los franciscanos, que también eran pobres. Por esa vía, se había entrado en los «méritos de la causa principal» pues con la firma de derecho se admitía que los franciscanos estaban en posesión de no pagar el impuesto del corte y que la causa era de naturaleza fiscal. No diferente, en fin, de las contempladas en el fuero 22 de I547, y, en consecuencia, de la absoluta competencia de los diputados "pues tienen concedida esta cognición con cláusula abdicativa por el fuero 33 de las Cortes de $1510 \% .^{40}$

Blanco había sustentado sus argumentos en la doctrina de Luis de Peguera, recogida por F. G. de León en su decisión II4, que defendía la

38. BHUV, varia 45 (27), f. 3 .

39. Ibidem, f. 4.

40. Ibidem, f. 7 . 
avocación de causas de comunidades eclesiásticas por la Real Audiencia, en razón del privilegio que disfrutaban por la lex Unica, C. quando Imperator inter pupilos et viduas ${ }^{4 \mathrm{I}}$ y una pragmática del emperador Carlos I. Como en los fueros del reino no se mencionaba, de manera explícita, ninguna comunidad eclesiástica, la causa de los franciscanos, en tanto que privilegiada, cumplía los requisitos para ser introducida en el alto tribunal del reino y sustraída de la jurisdicción de la Diputación. Evidentemente, Morlá no compartía tal planteamiento y, acogiéndose a la interpretación de Ulpiano de dicha lex Unica, C. quando imperator, negaba la necesidad de palabras expresas para la derogación del privilegio de las comunidades en cuanto a la avocación; bastaba que aquella se desprendiese del sentido e intención de la ley. Por ello, desde el momento en que se concedió a los diputados jurisdicción privativa en materia de impuestos del General, ninguna persona privilegiada, ni aun comunidad eclesiástica, en virtud del privilegio de la referida lex unica, podía declinar de su fuero, "pues por la concesión de la jurisdicción privativa cesó dicho privilegio de elección de fuero y dexaron de ser sus causas consistoriales». ${ }^{42}$

Frente a la posesión de exención inmemorial, esgrimida por S. Blanco en favor de la causa franciscana, Morlá enarboló la propia de la Diputación en cuanto a exigencia de tributos, también a los religiosos, como acreditaban las leyes patrias y la doctrina de dos reputados teólogos, Blas Navarro y Miguel Salon. ${ }^{43}$ Precisamente estos autores se ha-

4I. Consagraba el privilegio de elección de fuero. Fue otorgado por el emperador Constantino a favor de viudas y otras personas miserables en una constitución imperial del año 334. Se convirtió en centro del debate doctrinal que, varios siglos después, se produjo en torno a los límites y extensión de esta figura.

42. Ibidem, f. 9.

43. Dos figuras de reconocido prestigio y, en ambos casos, claros defensores de las obligaciones fiscales del clero. Juan Blas NAVARRo (¿?-1595), maestro en artes, catedrático de teología de la Universidad de Valencia y rector de la misma entre I571 y I576, prepósito y pavorde de la catedral, lo hizo en su obra Disputatio de vectigalibus et eorum iuxta exactiones in foro conscientiae, (Valencia, I578). Miguel Bartolomé SaLON (I539I62I), religioso agustino, maestro en artes, doctor en teología y en ambos derechos, catedrático en la Universidad de Valencia. Recibió el sobrenombre de «Salomón valenciano». Se le considera también fundador del Derecho internacional y autor de la escuela 
bían mostrado declarados defensores de la obligación del clero de contribuir a las cargas fiscales del reino en función del bien público y de la común utilidad de estas para la protección y defensa del clero y del pueblo. Y, en tal sentido, se invocaba una bula recientemente expedida por Inocencio X (Roma, 30 de marzo, I647) a petición de Felipe IV. Se había concedido para pagar la leva de mil doscientos soldados a la que el Reino de Valencia se comprometió en las Cortes de 1645 y en ella el Papa obligaba a todos los eclesiásticos a contribuir.

Al cierre de su digresión, Morlá, que conocía de primera mano las causas de los jerónimos de Cotalva y de los agustinos, explicaba los puntos que mantenían en común con la de los franciscanos. En todos los casos los agentes de la iuris firma eran comunidades religiosas y pretendían hacer valer el privilegio de causa consistorial de cara a la avocación. Dado que se les denegó a los primeros, privilegiando la jurisdicción privativa de los diputados, la misma resolución debía extenderse a los franciscanos spectata essentiali ratione. Restaba fuerza a la decisión I47 de Francisco J. de León utilizada en la argumentación de su contrario. Para el pavorde era «opinión muy probable, por la autoridad y letras de este grave Senado... pero no es aquella tan en su favor como se considera porque el averse evocado [sic] la causa del lugar de Torrente (del que habla dicha decisión) fue porque se trataba de interpretatione regii privilegii; y en este caso que sea consistorial, communis et vulgaris est practicorum cantinela. ${ }^{44}$ Por todo ello concluía que la causa de firma de derecho, presentada por el adversario en la corte del Gobernador sobre la pretendida posesión de no pagar los derechos del General, no era avocable por la Real Audiencia.

española de Derecho natural. Fue consultor del Santo Oficio; prior en varios momentos de los conventos de su orden en Valencia y provincial de I599 a I602. Es conocida su labor como teólogo consultor del arzobispo Ribera en el tema de los moriscos y biógrafo de santo Tomás de Villanueva. Su obra Controversia de Iustitia et Iure (Valencia, I59I; Venecia, I608) fue todo un referente en los debates sobre fiscalidad. En Vidal Guitarte IzQUIERDO, El pensamiento jurídico valenciano del siglo XII al XIX. Aportaciones a su Historia, Fundación Balaguer Gonel Hermanos, Castellón, 1986, pp. 89 y 106.

44. BHUV, varia 45 (27), f. I4. 
En la vertiginosa sucesión de alegatos que caracterizó la dinámica de esta fase final del proceso, la respuesta de Silvestre Blanco no se hizo esperar. ${ }^{45}$ Rehuyendo la reconducción de contenido señalada por su oponente, Blanco se centró, de nuevo, en la inmunidad fiscal de los franciscanos. No se ponía en duda la jurisdicción privativa de los diputados en causas afectas a la fiscalidad del general. La cuestión radicaba en que esa competencia solo podía ejercerse sobre quienes estaban sujetos a esta; así se recogía en los fueros que consagraron una competencia que no se discutía. ${ }^{46}$ Pero no era este el caso. La exención fiscal de los eclesiásticos era una «regla clara y universal que conocen todos los derechos» (f. 2); modificar esa situación requería autorización del romano pontífice y fue por ello por lo que Carlos I solicitó a Adriano VI la bula de I522. La duda que se planteaba en el presente caso era averiguar si en dicha bula estaban comprendidos los franciscanos. Al discrepar las partes enfrentadas en la que era la cuestión crucial de la causa, Blanco invocaba el recurso a Roma para la interpretación de la bula y, por ende, de los privilegios fiscales de la orden franciscana. ${ }^{47}$ Admitida la verdad de estos fundamentos, al abogado invocaba la autoridad del Real Consejo para decidir «en lo possessorio» (la materia de la iuris firma), aun entre eclesiásticos y cosas eclesiásticas y espirituales. Auto-

45. BHUV, varia 2 (30), Por la religión de la regular observancia del Seráfico P. S. Francisco con la Generalidad del Reyno de Valencia (s.f.).

46. Ibidem, f. 3. El autor entresacaba de las rúbricas de la recopilación de Mora de Almenar las expresiones que señalaban la situación por él expresada: «Los deputats hajen plen e bastant poder de compelir e estrenyer tots e sengles tenguts e obligats». $\mathrm{Y}$ : «contra omnes et quascumque personas quae ad contribuendum teneatur» (fuero I4 y ejecutoria de la oferta en Cortes I4I8).

47. Ibidem, f. 4: «la duda no nace de capítulo de la Diputación [...] sino de la dicha Bula de Adriano. Y así, para declarar si está comprehendida, o no, en ella nuestra sagrada religión ha de ser la interpretación de la misma Silla Apostólica que la concedió, y no de otro». Apoyándose en una amplia tratadística que reconocía este principio fundamental —y sobre todo en las tesis de Castillo de Bovadilla-, Blanco insistía: «en términos de constituciones, en orden a cosas eclesiásticas [...] de su interpretación o declaración, se recorra al que las concedió. Y en individual de letras, Breves o Bulas pontificias [...] toca a la Silla Apostólica». 
ridades como F. J. de León, Cáncer o Castillo de Bovadilla, sustentaban su argumentación. ${ }^{48}$

\section{Una solución «en tablas»}

El fallo de la causa entre la Generalidad y los franciscanos por el pago del impuesto del tall del drap transitó por dos instancias, ambas sustanciadas ante los diputados. En primera instancia la sentencia fue contraria a la orden..$^{49} \mathrm{Tal}$ resolución significaba un triunfo claro de la tesis sustentada por el pavorde Morlá en sus Alegaciones, donde se oponía a la firma de derecho y avocación de la causa por la Real Audiencia. Representaba, también, la estricta observancia de los fueros que consagraban la jurisdicción privativa de los diputados, evitando, de paso demoras en las ejecuciones contra los deudores del General y gastos procesales. ${ }^{5 \circ}$ Cuando el notario Tudon, en representación de la orden,

48. Ibidem, f. 5 .

49. BV, XVIII, I4O2 (7). Este documento que nos permite conocer el desenlace del caso compendia tres diferentes: la alegación elaborada por Luis Agramunt de Sisternes tras conocerse el fallo de la causa en primera instancia (Por la religión seráfica de san Francisco, con la Generalidad del Reyno (s.f.), ff. 55-62); la Sentencia donada per los senyors, reverents, nobles y magnifichs diputats, en favor de la religió del serafich pare sent Frances (I2 de noviembre, I66I), ff. 63-65; y la Sentencia donada per los molt magnifichs senyors iurats de la ciutat de Valencia, en favor de la religió del serafich pare sent Frances (19 de septiembre, 1656), ff. 66-67.

50. Inconvenientes muy bien señalados en la parte expositiva del fuero $22 \mathrm{de}$ I547, tantas veces invocado en la documentación comentada: «Item Senyor, per quant moltes vegades se segueix que algunes persones del dit Regne, per escusarse de pagar lo dret del General y per no servar ni obtemperar los actes de cort,crides,ni provisions, en virtut de aquells, per restańar dits drets y llevar tota ocasio de fraus fetes, se posen algunes escritures de fermes de drets, a suplicació dels quals per lo lochtinent general del dit Regne son estades evocades a la Real Audiencia; y jatsia dites causes, per observancia de dits actes de cort, se restituheixen als dits diputats, no res meyns ans de provehirse dita restitució se fa procés, his causen moltes despeses ultra la llarga detenció, per rahó de la qual la jurisdicció dels dits diputats y altres offcials del dit General en lo entretant está suplantada y la execució dels dits drets se perturba, en 
presentó recurso de apelación contra dicha sentencia, la causa entró en una segunda y definitiva fase. Los diputados seguían siendo la instancia competente para resolver la apelación, pero debieron modificar la composición letrada del tribunal. Antes de dar este paso, el referido Tudon había planteado otro recurso de apelación ante los jurados de Valencia (27 julio, I655), cuyo tribunal también había emitido sentencia contra los franciscanos obligándoles a pagar sisas municipales. ${ }^{\text {II }}$ Las dos apelaciones se resolvieron de manera favorable a la orden, pero en distintos tiempos. En septiembre de i656, fallaron en apelación los jurados de la ciudad de Valencia, asesorados por el abogado del municipio Donato Sánchez del Castellar. La sentencia obligaba a la ciudad a restituir al síndico de la orden las cantidades exigidas en concepto de sisa del tall (impuesta en las Cortes de I645) y cobradas indebidamente, porque, según se reconocía: «sent aixi que la dita religió y lo diner que es gasta en comprar los sayals son exemps de qualsevol genero de sisa, a ocasió de que així los sayals com los demes bens de dita religió serien propis de la sede Apostólica».52

El recurso ante los diputados tardó más en resolverse. El relato detallado que aporta la documentación procesal ${ }^{33}$ nos permite conocer la dinámica del procedimiento seguido y completar con ello un aspecto escasamente conocido por la falta de estudios al respecto. El fallo del tribunal en primera instancia contó con el asesoramiento del letrado Luis Pablo Viciedo, su asesor ordinario. ${ }^{54}$ La sentencia había determinado que los franciscanos, como el resto de religiosos, estaban comprendidos en la bula de Adriano VI y, en consecuencia, obligados a pagar derechos del General. Quedaba así justificado el embargo de sa-

gran dany e perjuhy de aquells...Supliquen...». En Mora de Almenar, Volum e recopilació, rub. II, p. 64.

5I. BV, XVIII, I4O2 (7), ff. 66-67.

52. Ibidem, f. 67.

53. Ibidem, ff. 63-65.

54. Graullera, Juristas valencianos, pp. 355-356, aporta datos curriculares de este jurista, doctor en Derecho y maestro en Artes, entre los cuales no figura su trabajo en la asesoría de la Generalidad valenciana que, sin embargo, si se acredita en la documentación procesal. 
yales ejecutado por los arrendadores del impuesto del tall del drap. Presentado el recurso de apelación en 24 de marzo de 1657, se nombró un nuevo asesor y dos letrados externos asociados al mismo. El nombramiento de asociados fue una petición del padre Cristóbal Salinas, ahora síndico y procurador de la orden para representarla en esta instancia. Los doctores Claudio Bertina y Juan Francisco de Villena asumieron dicho encargo. 55 Para reforzar las tesis de defensa de los franciscanos se encargó a Luis Agramunt de Sisternes la confección de una nueva alegación. ${ }^{56} \mathrm{El}$ letrado la construyó sobre la base de cuatro motivos, largamente explicados y fundamentados en su texto. Desde luego resultaron decisivos como demuestra el hecho de que la sentencia fallada en apelación los recogiera íntegramente.

Así, el dictamen publicado en I2 de noviembre de I66I reconocía que los franciscanos estaban exentos de tributar a la hacienda foral porque gozaban de la misma inmunidad que la bula de I 522 reconocía al santo padre. La exención franciscana de cualquier tipo de imposición se había establecido en tiempos de Sixto IV (Roma, I474) y nunca había sido derogada. Además, los impuestos recaían sobre bienes, los sayales, que los franciscanos no tenían: pertenecían al Papa; los religiosos hacían uso de estos a título de hecho, no de derecho. Por otro lado, aun reconociendo que los impuestos del General se establecían para atender necesidades comunes y que debían contribuir en ellos tanto los laicos como los eclesiásticos; sin embargo, la extensión de los gravámenes al clero requería autorización del sumo pontífice y ello no se había producido en el caso de los franciscanos cuyos bienes, se insistía, no les pertenecían. El argumento jurídico de que los impuestos del General se habían votado en Cortes y con el consentimiento del estamento eclesiástico tampoco podía admitirse en este caso; dejando de lado que en sede parlamentaria los eclesiásticos intervenían como barones, debía tenerse en cuenta que para que una imposición les afectase se necesita-

55. Dos abogados muy involucrados en la asesoría del municipio capitalino como se comprueba en sus curricula recogidos por GraUlLERA, Juristas valencianos, pp. I48-I49 y 359.

56. BV, XVIII, I4O2 (7), ff. 55-62. 
ba autorización papal. Casos recientes como las bulas de Inocencio X (I647) y Alejandro VII (I657), otorgadas para atender las necesidades suscitadas por pestes y levas militares, lo corroboraban. Y una situación tal no se había dado en I522.

El tribunal señaló también que la Generalidad no había demostrado estar en posesión inmemorial del derecho de exigir y cobrar impuestos a la orden. Se le suponía esa posesión, pero para aplicarla en esta causa debía probarla. Careciendo la orden de bienes, no se podía demostrar la posesión contra ellos, más aún cuando la bula de I522 establecía claramente que la facultad del General para exigir los impuestos a los eclesiásticos se limitaba a aquellos de quienes se podían reclamar y que con anterioridad hubiesen sido contribuyentes de su fisco. Correspondía a la Generalidad demostrar que antes de I522 había cobrado impuestos a los franciscanos, de lo cual no se tenía constancia. No podía presumir, pues, su «inmemorial» derecho fiscal ni esgrimir como argumento que también el monarca pagaba los derechos del General: aquel lo hacía por propia voluntad, según lo dispuesto en los fueros. E incluso, de no ser así, la sumisión del rey no obligaba al Papa y, con él a la comunidad franciscana. En consecuencia, el tribunal fallaba:

Pronunciam, sentenciam y declaram beneficio dictae appellationis, que deu ser revocada, segons que ab la present nostra difinitiva sentencia revocam, la donada per nos a consell del doctor Luch Pau Viciano, assessor ordinari nostre, de la qual se ha interposat la dita apelació per part del Sindich de la dita seráfica religió. Y axi mateix, que la instancia suscitada y moguda per lo dit Jusep Tudon, notari, dicto nomine en la dita suplicació de huit de juliol mil siscents cincuenta cinch, proceix y ha lloch de justicia et in consequentiam cancellam los embargos possats en los sayals de dits religiosos, taliter com si no se haguessen posat aquells et pari modo les obligacions y fiances donades per lo sindich de dita religió durante la lite per la seguretat de la paga del dit dret a prima usque ad ultima lineam et neutram partem in expensis condemnamus, lata, etc. ${ }^{57}$

57. Ibidem, f. 65. La sentencia fue firmada por el asesor de la causa Miguel Juan Moret, y los letrados asociados Bertina y Villena. 
La Generalidad (también el municipio capitalino, como hemos visto) había perdido definitivamente la batalla contra la inmunidad fiscal de los mendicantes franciscanos. En buena lógica y mejor derecho parecía una solución objetiva en razón de la extrema pobreza de la orden, su carencia absoluta de bienes y su dependencia estricta de las limosnas para sobrevivir. La derrota en este frente contrasta, no obstante, con la victoria obtenida con relación a los nuncios papales. Los escenarios de referencia se identifican con los registrados en la polémica con el clero regular pero el modus operandi varía sensiblemente.

En I650, don Cristóbal de Cardona, síndico de la Generalidad presentó Alegación en Derecho ${ }^{58}$ para oponerse a la orden de Felipe IV que pretendía obligar a la Diputación del reino a devolver al nuncio papal los impuestos cobrados a aquel por ropas y joyas enviadas desde Italia para uso propio suyo y de su casa. En cuanto el virrey, conde de Oropesa, puso en conocimiento de los diputados el mandato real, estos decidieron «rescribir a su Príncipe y señor» para plantearle la duda que tal orden les suscitaba. Sin juicio de por medio elaboraron la alegación en cuestión exponiendo las razones por las que no consideraban exento al nuncio. La tan traída bula de I522 volvía a entrar en escena con argumentos ya conocidos, como el de no mencionarse en ella la inmunidad fiscal de esta figura. Con fundamentos de derecho común y doctrina, se situaba la representatividad del nuncio en la persona que no en los bienes del Papa; y dado que solo estos últimos quedaban exentos de la fiscalidad del General, se justificaba el gravamen sobre las pertenencias del nuncio. Las disquisiciones doctrinales referidas en la alegación se sucedían en el escrito para terminar recogiendo el desenlace de otro intento similar acaecido en I642. La exención de impuestos del General entonces pretendida para el Patriarca de Constantinopla, nuncio extraordinario, se resolvió endosando al rey el importe correspondiente.

58. BHUV, varia 45 (29), Alegación en Derecho que a la Magestad del rey nuestro señor presenta Don Christoval de Cardona, cavallero del abito de Montesa y sindico de la generalidad del reyno de Valencia sobre la inmunidad y exención de derechos del General que pretende gozar el Nuncio y legado a latere de su santidad en estos reinos de España (Valencia, I650). 
Era, a juicio de la Diputación, lo que también procedía en este caso. ${ }^{59}$ En definitiva, aunque ahora no se expresase, la solución aplicada coincidía con la establecida en el reinado de Felipe II para los miembros del Santo Oficio: privilegio fiscal, sí, pero asentado en la cuenta del monarca.

Las fricciones entre el Estado eclesiástico y la Diputación parecen persistir hasta las postrimerías del régimen foral. No de otro modo cabe explicar el sentido del extensísimo Memorial elaborado por Vicente Clavero de los Porcells en defensa de la competencia de los diputados para perseguir y castigar a los eclesiásticos que defraudaban los derechos del General. ${ }^{60}$

La batalla judicial librada a propósito de todos estos conflictos sirvió para confirmar y salvaguardar la jurisdicción privativa de la institución en materia tocante a su fiscalidad. La cuestión de la exención fiscal que aquí hemos abordado permite afirmar la limitación de esta, en la práctica, a muy concretas situaciones y colectivos. Descubre, asimismo,

59. En I644 Felipe IV intentó también el libre pasaje de las pertenencias del nuncio cesante, el cardenal Pansiloro, y de su sucesor, el obispo de Tarsis. A tal efecto, dirigió las correspondientes misivas al virrey de Valencia, duque de Arcos, para que transmitiese su decisión a los diputados del reino. En AHNOB, Baena, C. 45, D. 23-26.

6o. BHUV, E 986 (6), Memorial al rey nuestro señor sobre que los muy reverendol reverendos, muy ilustre e ilustres, nobles y magnificos diputados del fidelisimo Reyno de Valencia son juezes competentes para executar a los eclesiásticos que defraudan los derechos de la Generalidad, las penas pecuniarias impuestas en los capitulos y condiciones de dichos derechos. El impreso carece de fecha de publicación, pero se considera anterior a I70I. Se elaboró a propósito de la oposición del arzobispo de Valencia a que se ejecutase sobre un presbítero y beneficiado de la iglesia de san Miguel de la ciudad de Valencia, la pena pecuniaria impuesta por los diputados del General al hallarse en poder del referido clérigo piezas de telas sin los plomos que identificaban el pago del correspondiente impuesto. A lo largo de los 84 puntos que lo componen se hace una completa disertación de los motivos que obligaban a los eclesiásticos a contribuir, su sumisión a las leyes civiles y, por ende, al príncipe fuente de toda ley; la equiparación de la fiscalidad del General con la regia y la competencia de los diputados como jueces ejecutores de las penas contra los defraudadores, cualquiera que fuese su condición y estado. Su autor, Clavero dels Porcells, se doctoró en la Universidad de Gandía en I668; fue abogado patrimonial de I682 a I70I, fecha de su muerte. En GraULLERA, Juristas valencianos, pp. I67-I68.

Pedralbes, 40 (2020), 257-285, ISSN: O2II-9587, DOI: IO.344/PEDRALBES2O2O.4O.IO 
el escaso margen de maniobra que tuvo la propia monarquía para conseguir dejar fuera del fisco regnícola a miembros de instituciones o figuras que, por cuestión de oportunidad o criterio particular, considerase debían quedar exentas. El fisco del reino no exoneraba al rey, quien, además, debió cubrir con fondos propios el privilegio de inmunidad solicitado para terceros. 